\title{
[Letter to the Editor] \\ The need for improved education and training in research antibody usage and validation practices
}

Antibodies are indispensable biological reagents in basic and translational research laboratories, as well as in clinical settings around the world. Research antibodies can be classified into the following major categories according to production method (ranging from oldest to most recent technologies): polyclonal, monoclonal, and recombinant (1,2). Antibodies are used for a wide variety of biomedical research applications and assays, particularly Western blotting, immunoprecipitation, flow cytometry and fluorescence-activated cell sorting (FACS), immunofluorescence (IFA), immunohistochemistry and immunocytochemistry $(\mathrm{IHC} /$ ICC), enzyme-linked immunosorbent assay (ELISA), and microscopy. The growing scale of antibody usage is reflected by global sales, estimated at $\$ 1.6$ billion in 2011 (with U.S. sales of $\$ 700$ million) (1) and predicted to rise to $\$ 2.6$ billion by 2019 (www.marketsandmarkets.com/ PressReleases/antibody-production.asp).
Although of fundamental importance in preclinical research, antibodies are also a major contributor to the current reproducibility crisis $(3,4)$, where issues associated with the use of biological reagents and reference materials, particularly antibodies (5-7) -the most broadly used class of protein binding reagents (8)-continue to emerge. A key challenge for antibodies is their universal availability from hundreds of vendors - the vast majority of which are duplicates due to cross-licensing by antibody producers, generating enormous controversy and a pervasive lack of trust in their specificity and quality control (9). At the same time, many biomedical journals omit key protocols and biological resource information in publications where antibodies are utilized. A 2013 study found that only $44 \%$ of antibodies described in a survey of 200 biomedical papers could be uniquely identified (e.g., provided the vendor name and catalog number) (10).
Although multiple online antibody registries and databases have emerged, including Antibodypedia (www.antibodypedia.com/) (11), CiteAb (www.citeab.com/) (12), and the broader Biocompare (www.biocompare. $\mathrm{com} /$ ), to date, none have gained traction in the biomedical research community (5).

There are currently no standardized and widely accepted guidelines for antibody validation, although some approaches have been proposed, such as by Bordeaux et al. (13) and more recently by Roncador et al. (14). In 2014, the Global Biological Standards Institute (GBSI) formed a Research Antibodies and Standards Task Force to examine: (i) specific areas where standards for research antibody characterization and validation are urgently needed; (ii) what types of standards could be designed and implemented to address these needs; and (iii) how these recommendations can be implemented to advance the availability and use of

How often do you perform the following antibody-based applications?

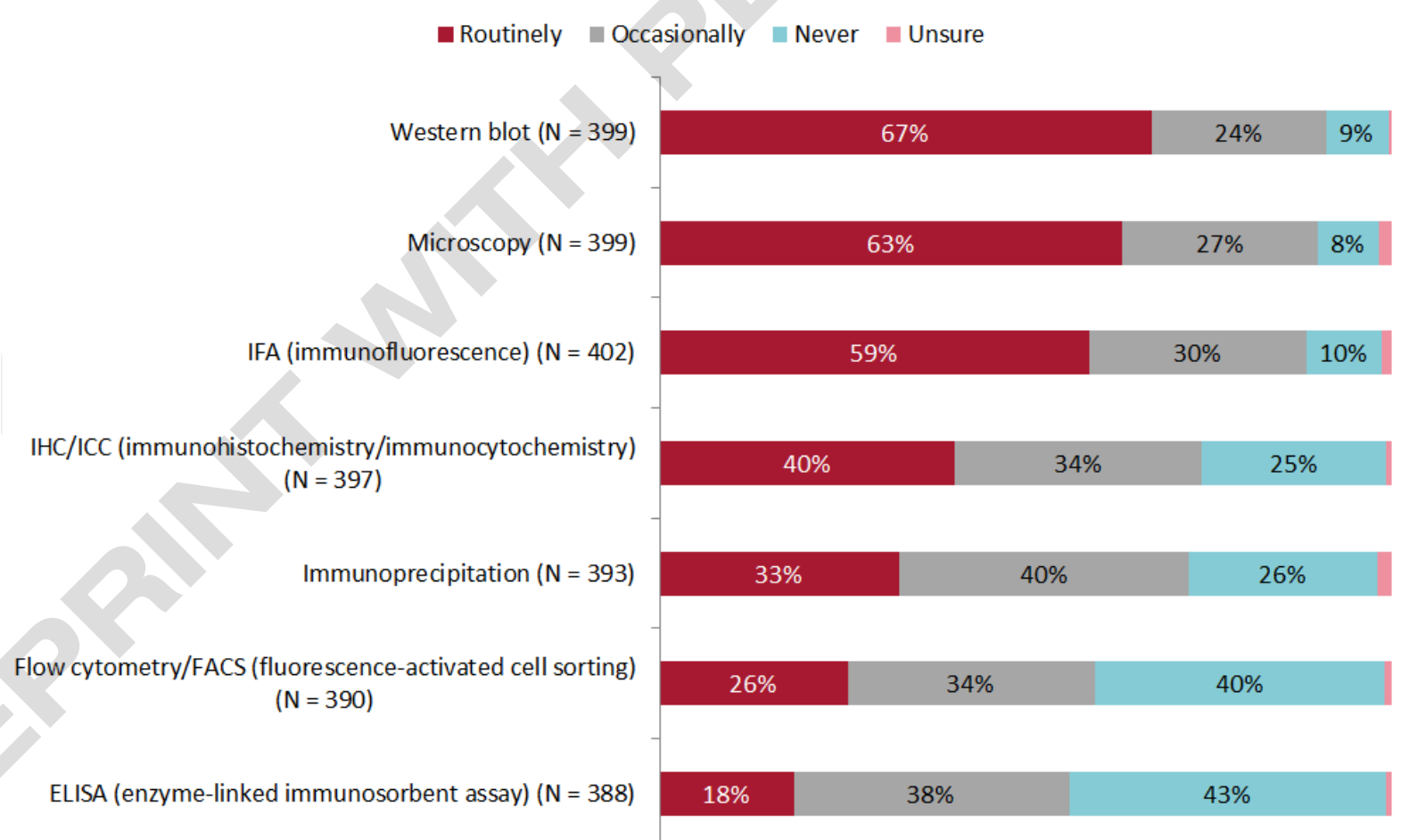

Figure 1. Frequency of use of most commonly performed antibody-based applications. 
Validation of antibody sources by tenure $(N=388)$

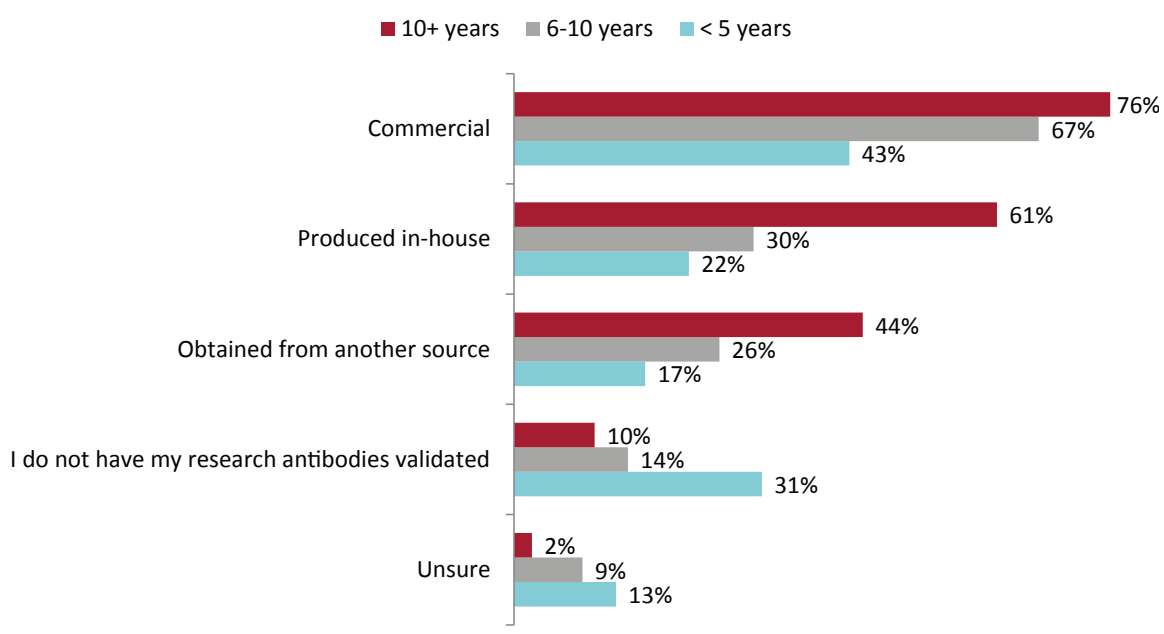

Figure 2. Validation of antibody sources by respondents' years of experience. reliable, high quality antibodies across the biomedical research community. To gain further insight on general research antibody usage and validation practices within the life science community, the GBSI task force designed and fielded an online, anonymous survey from April 16 to June 5, 2015. Here we report and discuss the findings of this survey. A summary of responses to all survey questions is provided in the Supplementary Material.

Of 504 total respondents, over half (58\%) reported themselves as senior (15+ years since completing training) or mid-career (6-15 years since completing training) researchers. The majority of survey respondents conducted basic research (90\%) and worked in academia (74\%). Forty-one percent (41\%) and 37\% reported using antibodies daily or weekly to support their research, respectively. The most commonly performed antibody-based applications were Western blotting, microscopy, and IFA (Figure 1).

Regarding usage patterns, $>80 \%$ of respondents reported using 21-100 antibodies on an annual basis, while $7 \%$ use $>100$ antibodies. Although $49 \%$ spend $>\$ 5000$ on antibodies per year, $41 \%$ of respondents spend $<\$ 1000$ per year on antibody-related quality controls and testing (such as application-specific validation), and $21 \%$ were unsure of such expenditures. The majority of respondents (83\%) obtained more than half of their antibodies from commercial sources.

When it came to obtaining information on antibodies, nearly all respondents (96\%) indicated that past performance influenced purchasing decisions from a particular vendor. While most antibody vendors provide guidance on antibody usage for specific applications, $85 \%$ of respondents ranked this guidance as low or moderate in accuracy and reliability. One-third (33\%) of respondents indicated that they typically screen 3-4 antibodies to find a "good" one, and half (52\%) have to screen 1-2. Interestingly, even though several online reference and performancerelated databases exist to support antibody identification, validation, and best practicerelated purposes, other than Biocompare, which was used by $41 \%$ of respondents, most survey respondents were unaware of or do not rely on any non-vendor antibodyspecific databases.

The final third of our survey focused on research antibody validation practices among scientists. The inability of investigators to replicate published data can often be traced to false-positive or falsenegative results produced with antibodies that were not properly validated to demonstrate specificity, selectivity, and reproducibility in the context for which they were used $(13,15)$; or to different lots of antibodies that may not have been validated (16). Even when validation data are provided by a vendor, this information is typically inadequate and frequently unreliable and historical, not referring to the actual purchased lot $(2,15)$. A widely cited external validation of almost 5500 routinely used commercial monoclonal and polyclonal antibodies from 51 different antibody providers found success rates varied dramatically by provider, ranging from consistently excellent (100\%) to consistently dismal (0\%), with an average success rate of $49 \%$ (17). Only half (50\%) of survey respondents reported routinely purchasing antibodies based on vendorsupplied validation data, instead primarily relying on literature citations (79\%), application-specific data (76\%), and Western blot/ELISA data (74\%). Most (87\%) respondents who validate antibodies do so internally, rather than externally such as on a fee-for-service basis.

When it comes to who is most likely to validate antibodies, Figure 2 illustrates that although $70 \%$ of respondents report validating or having commercial antibodies validated, less than half $(43 \%)$ of junior researchers ( $<5$ years of tenure) report validating purchased antibodies, and only $22 \%$ report validating antibodies produced in-house. Perhaps more surprisingly, a third of junior scientists do not validate at all (Figure 2). Given that issues

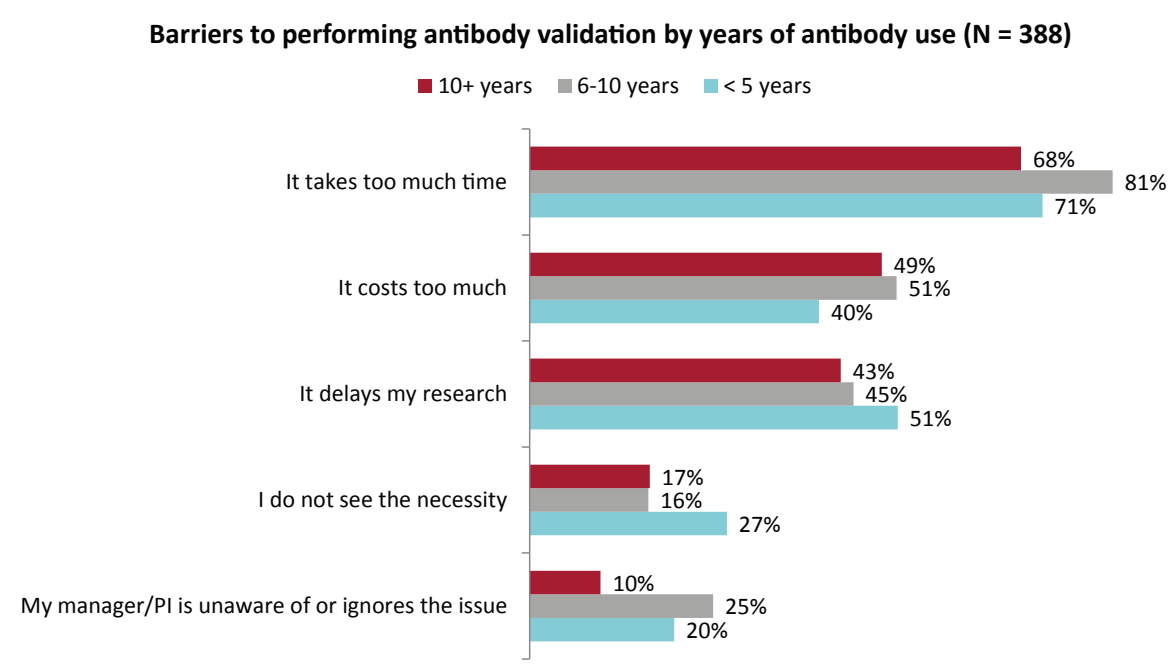

Figure 3. Barriers to performing antibody validation by the respondents' years of antibody use. 
surrounding antibody quality and validation have been prominently discussed in the scientific literature and media for at least the past decade, this finding would suggest many junior scientists are not receiving the necessary training in experimental design as well as in the selection, handling, application, and reporting of research antibodies and other biological reagents.

It is crucial to understand that a wide variety of issues can jeopardize antibodydependent experiments, including inactivation due to age, instability, or inappropriate storage and handling; poor choices of antibody type; incorrect dilutions or sub-optimal signal-to-noise titration; and antibodies that do not (or no longer) perform as advertised due to flawed specifications or batch-to-batch variations (2). Moreover, unique antibody products are often application-specific (e.g., Western blotting versus $\mathrm{IHC}$ ). In our survey, Western blotting was the most commonly used validation technique (Figure 1), but 33\% of respondents reported that their validation procedure did not differ or were unsure if it differed depending on the assay.

Figure 3 describes the perceived barriers to validating research antibodies and conducting quality control measures by years of antibody use. Consistent with the results in Figure 2, a clear trend emerged based on years of experience: over one-fourth (27\%) of researchers with $<5$ years of experience using antibodies indicate that they "do not see the necessity" of performing antibody validation. Additional perceived barriers, such as it "takes too much time" (71\%) and "delays my research" (51\%), imply that a "hyper-competitive" biomedical research environment (18) is having a negative impact on proper antibody validation practices-particularly among younger scientists who are often in the process of establishing their own labs. The fact that a majority of this junior-tenure category cites validation as an obstacle that delays their research can be interpreted as a general lack of understanding of the necessity of proper validation methodologies. Significantly, less than half of the respondents (44\%) reported receiving specific training (e.g., from their mentor or lab manager) on the importance of validating research antibodies and how to do so for specific applications.

Taken together, our survey results point to an urgent need to (i) improve the education and training of junior scientists in application-specific antibody validation and (ii) develop validation methodologies and best practices that are rapid, simple, and cost effective, in part to counter an apparent perception of antibody validation delaying rather than facilitating research progress. The biomedical research community must commit sufficient time, resources, and expertise to educate and train scientists-particularly junior researchers - in best practices for antibody-based experiments, reporting, and the importance of application-specific validation.

\section{Author contributions}

M.G. designed the survey and wrote the initial draft. L.F., A.R.M.B., A.M.B., D.D., M.D-F., F.L-J., and D.R. revised the paper.

\section{Acknowledgments}

We thank the staff of McKinley Advisors for their invaluable assistance in hosting, launching, and analyzing the results of our survey. We also thank Simran Kaur, former GBSI post-doctoral Research Associate, for her early support in developing the survey.

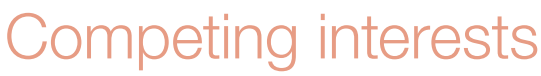

The authors declare no competing interests.

\section{References}

1. Bradbury, A. and A. Plückthun. 2015. Reproducibility: standardize antibodies used in research. Nature 518:27-29.

2. Voskuil, J. 2014. Commercial antibodies and their validation. F1000Res. 3:232.

3. Begley, C.G. and J.P. loannidis. 2015. Reproducibility in science: improving the standard for basic and preclinical research. Circ. Res. 116:116-126.

4. Freedman, L.P., I.M. Cockburn, and T.S. Simcoe. 2015. The economics of reproducibility in preclinical research. PLoS Biol. 13:e1002165.

5. Baker, M. 2015. Reproducibility crisis: blame it on the antibodies. Nature 521:274-276.

6. Marx, V. 2013. Finding the right antibody for the job. Nat. Methods 10:703-707.

7. Perkel, J.M. 2014. The antibody challenge. Biotechniques 56:111-114.

8. Bradbury, A.R. and A. Plückthun. 2015. Getting to reproducible antibodies: the rationale for sequenced recombinant characterized reagents. Protein engineering, design \& selection. PEDS 28:303-305.

9. Couchman, J.R. 2009. Commercial antibodies: the good, bad, and really ugly. J. Histochem. Cytochem. 57:7-8

10. Vasilevsky, N.A., M.H. Brush, H. Paddock, L. Ponting, S.J. Tripathy, G.M. LaRocca, and M.A. Haendel. 2013. On the reproducibility of science: unique identification of research resources in the biomedical literature. PeerJ 1:e148.
11. Björling, E. and M. Uhlen. 2008. Antibodypedia, a portal for sharing antibody and antigen validation data. Mol. Cell. Proteomics 7:2028-2037.

12. Major, S.M., S. Nishizuka, D. Morita, R. Rowland, M. Sunshine, U. Shankavaram, F. Washburn, D. Asin, et al. 2006. AbMiner: a bioinformatic resource on available monoclonal antibodies and corresponding gene identifiers for genomic, proteomic, and immunologic studies. BMC Bioinformatics 7:192.

13. Bordeaux, J., A. Welsh, S. Agarwal, E. Killiam, M. Baquero, J. Hanna, V. Anagnostou, and D. Rimm. 2010. Antibody validation. Biotechniques 48:197-209.

14. Roncador, G., P. Engel, L. Maestre, A.P. Anderson, J.L. Cordell, M.S. Cragg, V.C. Serbec, M. Jones, et al. 2016. The European antibody network's practical guide to finding and validating suitable antibodies for research. MAbs 8:27-36.

15. Schonbrunn, A. 2014. Editorial: Antibody can get it right: confronting problems of antibody specificity and irreproducibility. Mol. Endocrinol. 28:1403-1407.

16. Pozner-Moulis, S., M. Cregger, R.L. Camp, and D.L. Rimm. 2007. Antibody validation by quantitative analysis of protein expression using expression of Met in breast cancer as a model. Lab. Invest. 87:251-260.

17. Berglund, L., E. Bjorling, P. Oksvold, L. Fagerberg, A. Asplund, C.A. Szigyarto, A. Persson, J. Ottosson, et al. 2008. A genecentric Human Protein Atlas for expression profiles based on antibodies. Mol. Cell. Proteomics 7:2019-2027.

18. Alberts, B., M.W. Kirschner, S. Tilghman, and H. Varmus. 2014. Rescuing US biomedical research from its systemic flaws. Proc. Natl. Acad. Sci. USA 111:5773-5777.

Leonard P. Freedman', Mark C. Gibson', Andrew R.M. Bradbury², Arthur M. Buchberg ${ }^{3}$, Darryl Davis ${ }^{4}$, Marisa P. Dolled-Filhart 5 , Fridtjof Lund-Johansen ${ }^{6}$, and David L. Rimm ${ }^{7}$

${ }^{1}$ Global Biological Standards Institute, Washington, DC, ${ }^{2}$ Los Alamos National Laboratory, New Mexico, ${ }^{3}$ American Association for Cancer Research, Philadelphia, PA, 4Janssen R\&D LLC, Spring House, PA, ${ }^{5}$ Merck, Rahway, NJ, 'O Oslo University Hospital, Norway, and ${ }^{7}$ Yale University, New Haven, CT

BioTechniques 61:16-18 (July 2016) doi 10.2144/000114431

Keywords: antibodies; preclinical; reproducibility; survey; validation

Supplementary material for this article is available at www.BioTechniques.com/article/114431.

Received 19 February 2016; accepted 08 April 2016.

Address correspondence to Leonard P. Freedman, Global Biological Standards Institute, 1020 19th Street, NW, Suite 550, Washington, DC, 20036. E-mail: Ifreedman@gbsi.org

To purchase reprints of this article, contact: biotechniques@fosterprinting.com 